\title{
THE IMPACT OF RESPONSIVE SYSTEMS ON ENERGY CONSUMPTION AND THERMAL PERFORMANCE OF BUILDINGS
}

\author{
Manar Mohamed Fouad ${ }^{1}$, . Vitta Abdel Rehim Ibrahim ${ }^{2}$ \\ and Ahmed Hosny Radwan ${ }^{3}$ \\ ${ }^{1}$ Architecture Department, B.sc. in Architecture, P.H.I for Eng. and Technology - 2016 \\ ${ }^{2}$ Architectural Design, Pyramids Higher Institute For Engineering \& Technology, Giza, Egypt \\ ${ }^{3}$ Architecture \& Urban Design ,Faculty of Fine Arts, Helwan University, Cairo, Egypt \\ Arc.manar_eltanboly@yahoo.com, vitta226@gmail.com, ahosney@gmail.com
}

\begin{abstract}
It is easy today to predict that the building systems will become active in the responsive system operation by controlling their energy consumption to optimize complex criteria beyond ensuring local end-use comfort satisfaction. It's necessary to enable integration between the building and the surrounding environment. So, Responsiveness in architecture is one of the attributes that you can apply. Studies have shown that the biggest reason for this, billions of people will live in cities especially in Asia and Africa, and most cities are not ready for this massive growth, it's hard to show buildings and more damage to the environment, cause our cities to emit $80 \%$ of greenhouse gases industry, transportation and Mobility. So, it should use natural resources to reduce energy consumption that seeks sustainable building design. Cities are not only the hotels, but it's placed to live in order to influence and improve their characteristics. This study is a part of a thesis titled "Analytical study of responsive architecture and smart materials and their impact on environmental design" and it aims to understand and multiple forms of architectural response such as a kinetic facades or human interface with the building to generate energy or use local building materials which reduce energy consumption and resources. We have to work on the future cities to achieve livability and responsiveness it's become first for a smart, So it's important to know the architecture information and Knowledge. This paper aims to know how to reduce energy consumption in buildings according to use a responsive system in architecture to achieve this and improve the efficiency and thermal performance of buildings.
\end{abstract}

KEYWORDS: Responsive Architecture, Human interactive, Environmental design, Kinetic, Design efficiency.

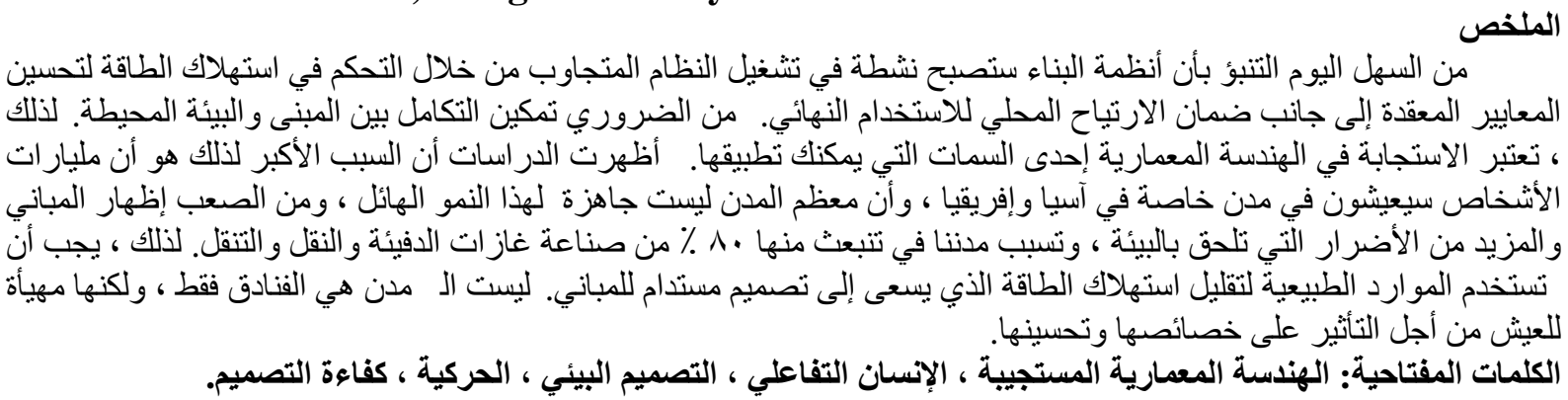
1-INTRODUCTION :

Buildings contribute to generating a large amount of all electricity consumption in our countries ,The transformation of the building systems from passive, although efficient, consumers to active participants in the smart system constitutes a significant element towards improving grid resilience to extreme weather events and operation reliability in presence of large renewable integration. Responsive buildings enable a physical response to changes in the environment through building elements; in rare cases these responsive elements become an integral of a culturally significant work 


\section{THE IMPACT OF RESPONSIVE SYSTEMS ON ENERGY CONSUMPTION AND THERMAL PERFORMANCE OF BUILDINGS}

of architecture. Responsive architecture adapts to the surrounding environment causing an alteration in the envelope configuration to perform not only depend on adaptation, but a reaction to certain external circumstances in a more effective way. Building's main purpose is protecting the occupancies from the external surrounding environment and achieving a comfortable indoor environment . The cooling and heating energies of the building will be compared in two different conditions, one with its current state, which is without responsive architecture and other after applying three different types of responsive architecture on it. Nowadays, large numbers of buildings are designed without taking into consideration the surrounding environmental conditions. As a result, the building envelope should be designed to be a great potential for energy saving and react with these alterations (Modin, H., 2014). So, moving elements are not a recent phenomenon in the building sector. The development in the field of robotics and electronics has made it possible for the architectural elements to move, and to respond easily to the alteration of the external surrounding natural environment. the possibilities of responsive materials and responsive buildings envelopes can play a great role in the reduction of energy efficiency.

\section{- 1.1-Research Problem:}

A lot of buildings are not designed to adapt to the process of changing of surrounding environment. As a result, they use excessive energy systems. Thus large amounts of energy are being consumed and the rates of the energy consumption are increasing rapidly which causes climate change and environmental pollution by the raising in $\mathrm{Co} 2$ ratio. There is an urgent need to design buildings to interactive to the surrounding environment. One of the main central reasons for the current environmental pollution problem is the excessive use of energy in buildings. Burning fossil fuels to obtain electricity caused pollution of the air, water and soil. Also, it is considered the main responsible for global warming (Bearden, 2000).

\section{- 1.2-Research Aim:}

The aim of the paper is explaining the relationship between responsive architecture and surrounding environment and the impact of responsiveness in environmental design, thus reduces the environmental pollutions and the energy consumption to improve the thermal performance of buildings.

- 1.3-Research Objectives:

- Determine the most efficient type of responsive architecture to reduce energy consumption.

- Determine the percentage of reducing energy consumption due to applying responsive techniques.

- 1.4-Research Methodology:

The research tries to evidence that responsiveness in architecture can reduce energy consumption and effect to the thermal performance of buildings. Added to this, it will result clarifying the most efficient type of responsive systems in reducing the energy consumption.

\section{- 1.5-Research Structure:}

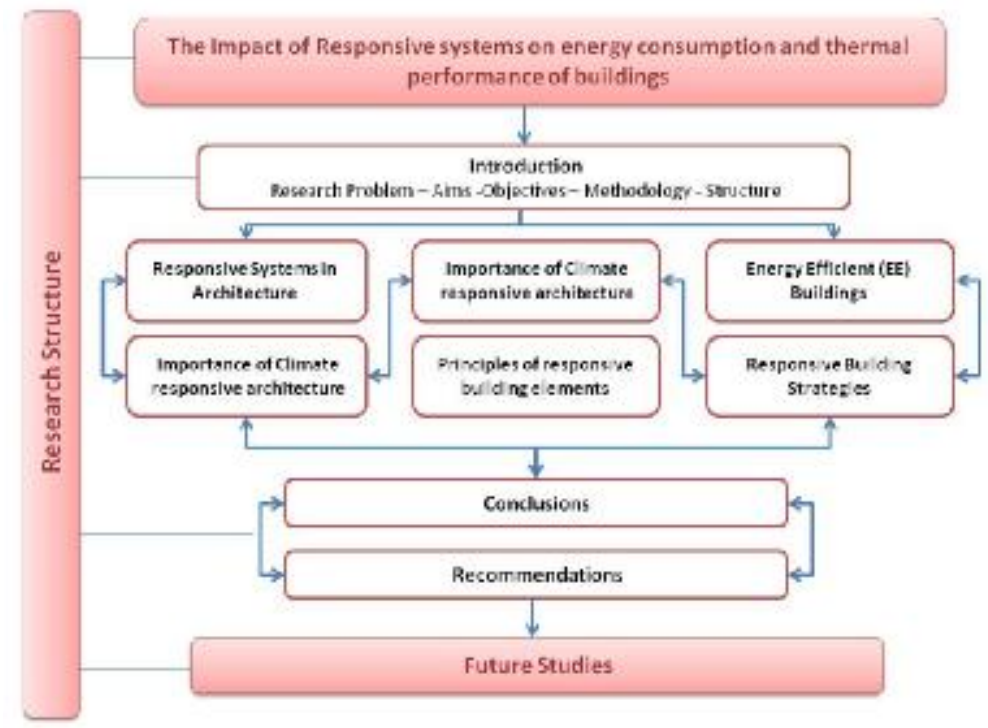

Figure (1): Structure of research ource: By Author 
- 2- Responsive systems in Architecture:

The responsive architecture was introduced by Nicholas Negroponte, who first conceived of it during the late 1960s when spatial design problems were being explored by applying cybernetics to architecture . Negroponte also extends this mixture to include the concepts of intention, and meaning into computing and its successful (ubiquitous) integration into architecture .According to Tristan d'Estree Sterk, Responsive architecture is defined as " a class of architecture or building with the objective of physically reconfiguring themselves to meet changing needs with variable mobility, location or geometry"( Addington M., Schodek, D.,2005)

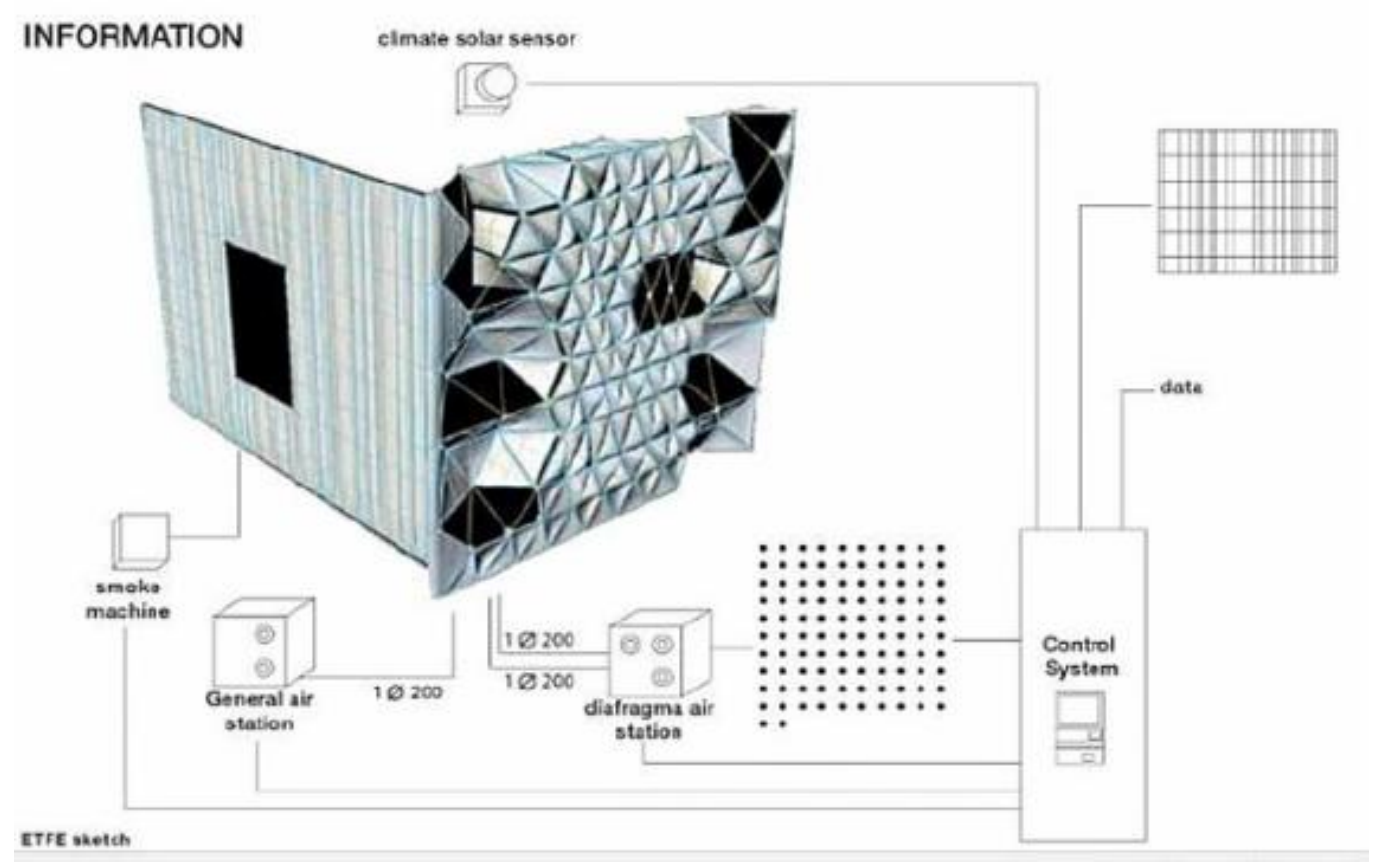

Figure (2): Responsive Technology by Sensors Source: www.arch.tuc.gr

Responsive architectures aim to refine and extend the discipline of architecture by improving the energy performance of buildings with responsive technologies (sensors/ control system/ actuators) while also producing buildings that express the technological and cultural circumstances of our time. For example: by the integration between a responsive technology , and the structural systems of buildings architects have the ability to tie the shape of a building directly with the environment.

\section{- 2.1- Integration of technology in Responsive Architecture:}

Responsive Architecture is the form of Architecture that integrates technology so well into the form and functions of designed structures in order to allow such structures to overcome the outstanding challenges posed by its Environment and microclimate.

The responsive architecture enables the architect to design structures that can learn to adjust to the environmental requests and the changes in the needs of the user through the help of suitable technologies. 

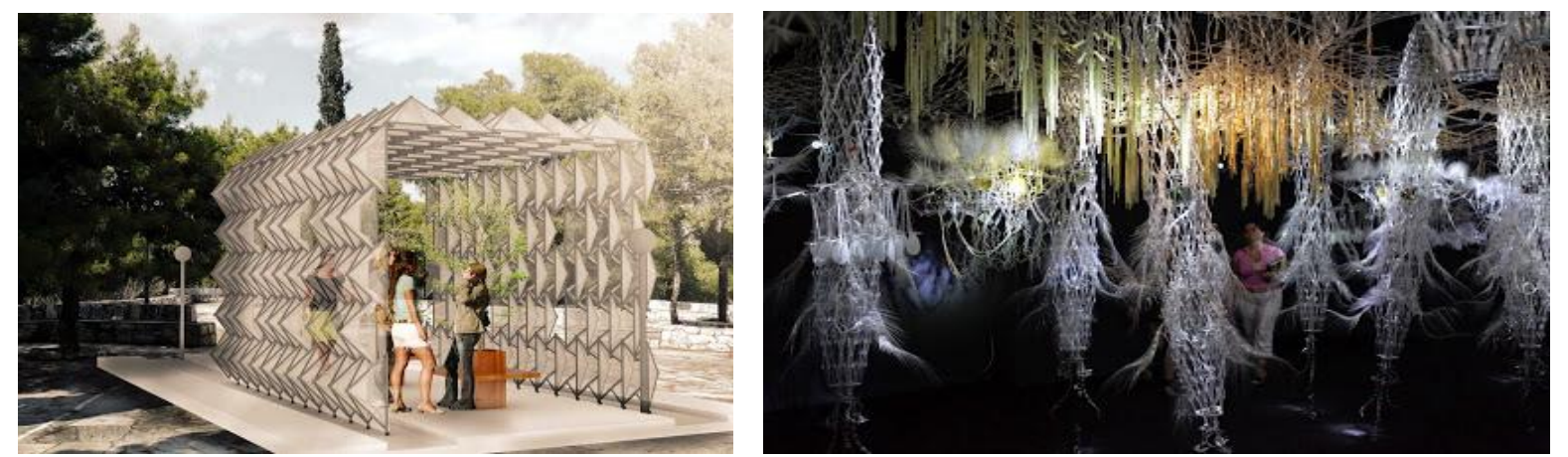

Figure (3): Responsive architecture and suitable technologies .

Source: architecture.blogspot.com

It seeks to establish a perfect symbiotic relationship between Technology, Structures, Nature, Humans, Building Materials, building , and Environmental forces to produce an Architectural solution that can learn to solve problems on its own. The thermal performance problems of buildings can be solved using responsive systems. The building design and its facade should be more concerned with the environmental conditions and the environmental loads, the less time may be needed a mechanical system to maintain zone and less energy will be consumed.
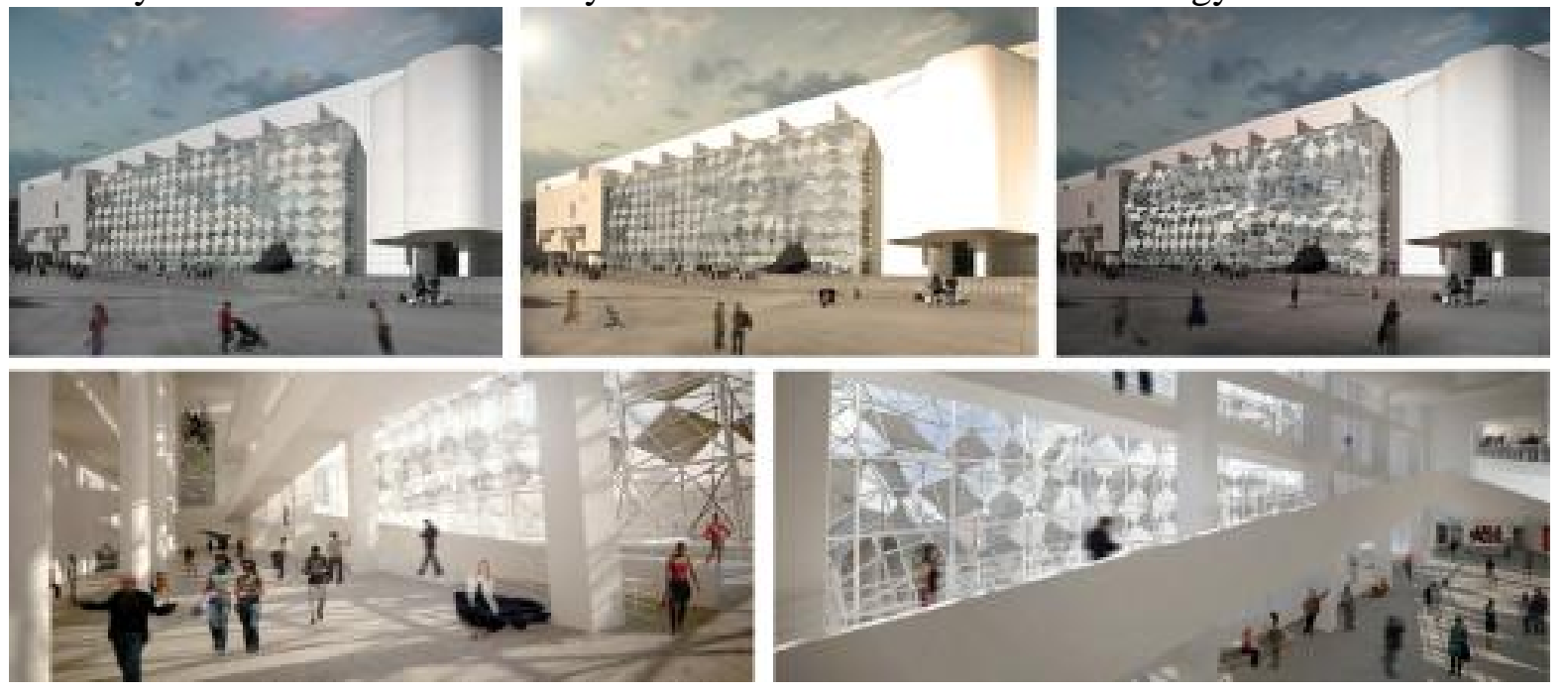

Figure (3) : Responsive building skin designed for MACBA, Barcelona, by rat[LAB] - Sushant Verma \& Pradeep Devadass in research adaptive[skins] carried out at AA London-Em.Tech. Source: www.arch20.com/responsive-to-adaptive-the-shifting-trends-in-architecture

So, contemporary architecture has introduced Kinetic movements as a process of self adaptation and responsiveness. Having the possibilities of 21st-century computing power, it developed a discrete model of architecture consisting of a multitude of sensors, processors and actuators, conducted by hybrid control networks and embodied in an alterable structure of temerity elements. In this explanation, the model of control has three major parts:

1 - The user entry, which gives the users the possibility of controlling or tampering responses that extend throughout the building.

2- Building a structure with responsive capability to respond directly to environmental loads. 3-Spatial responses that are used to control the partitioning and servicing of internal space. 

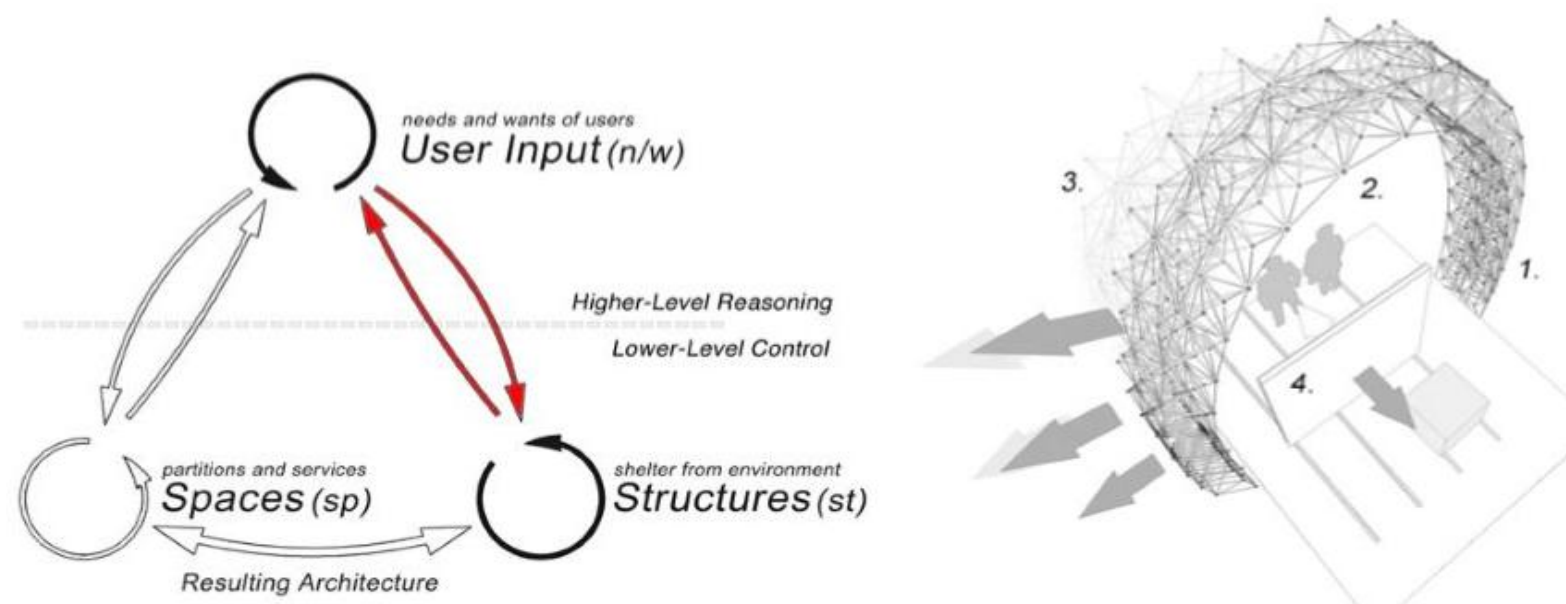

Figure (4): Proposed hybridized control model for use within a functional responsive architecture , Structure and internal partition working cooperatively in response changing patterns (Courtesy of Tristan d'Estrée Sterk)

Sterk points out that in responsive architecture the next architectural state of a building is determined by the concept to "treat the needs and wants of users as a set of ever-changing conditions." As the architectural state is to be in flux, space transforms from a former static modular order into a topological field which responses to bodily activity. The setting of responses is dependent on satisfying very substantial questions about person-environment relationships, sustainability and the lifestyle of users. Thinking in scenarios reveals the different levels of a possible engagement of responsive architecture. Further, it leads to an analysis of relations that can be established with such a techno-environment.

\section{2- Responsiveness To Environment interface:}

The responsive system deals with any building component that can change and reform itself in response to human needs. they can refigure itself to adapt to environmental purposes, aesthetical purposes and user's interaction purposes. They can adapt to the surrounding environmental by whether changing its geometric patterns or by changing the properties of the facade's material. they can reform its shape for aesthetical purposes and forming an iconic building, or for interacting with the users and grapping their attention. The buildings can respond and adapt to the surrounding weather and environment in order to increase the building performance and reduce the entered solar radiation. The following two sections investigate different buildings that used these two techniques.

- 2.2.1- changing geometric patterns:

this type of responsiveness to environment interface depends mainly on changing the fragments and patterns on the facade. the building is divided into patterns which change their location in order to reduce the solar radiation entering the building.

The following examples have used this type : (Institute of the Arab world / Media-TIC ) .

\subsubsection{1- Institute of the Arab world, Paris 1981 to 1987:}

Thirty years after its inauguration and still one of important building in the world, It is characterized by a unique and important element that is the mashrabiya: This emblematic feature of the building was designed to open and close depending on the amount of daylight, but the mechanism ceased to function. The building will henceforth become a Parisian visual landmark again, day and night. 

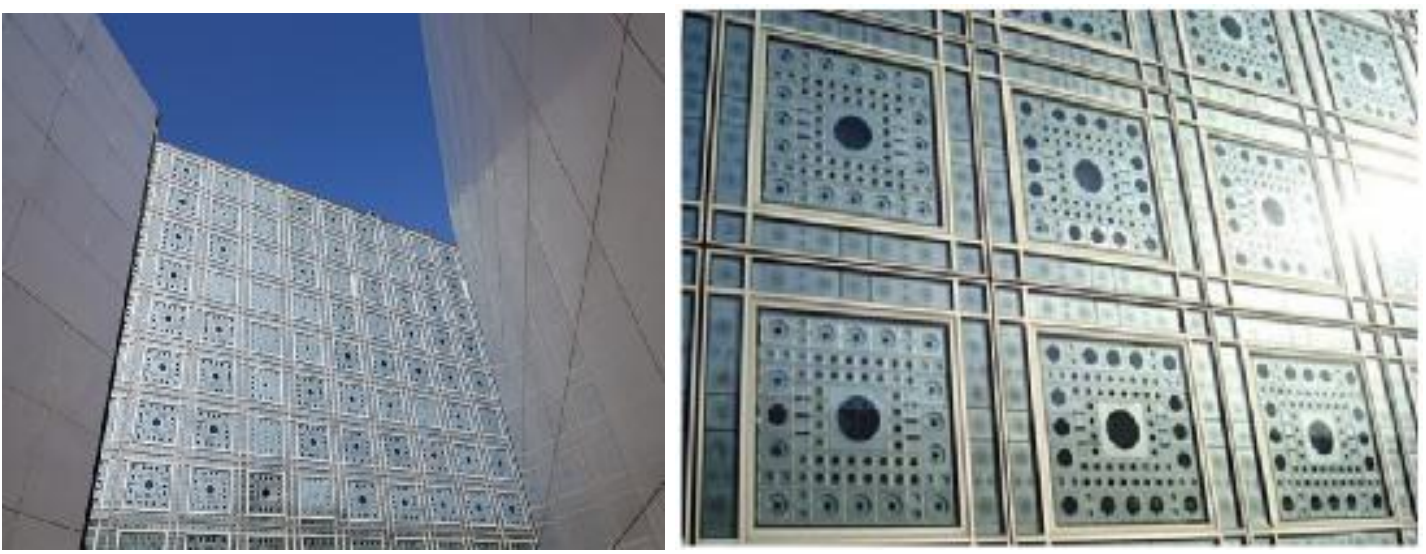

Figure (5): Institute of the Arab world appear the main concept of the mashrabiya Source: www.flickr.com - www.imarabe.org

\subsubsection{2- Southern Denmark University Building, Kolding 2014:}

The solar shading system is fitted with sensors which continuously measure light and heat levels and regulate the shutters mechanically by means of a small motor. It simulates how thermal properties of concrete can be increased - and the energy consumption for heating and cooling thus reduced. This prevents large fluctuations in temp. and improves the indoor quality.

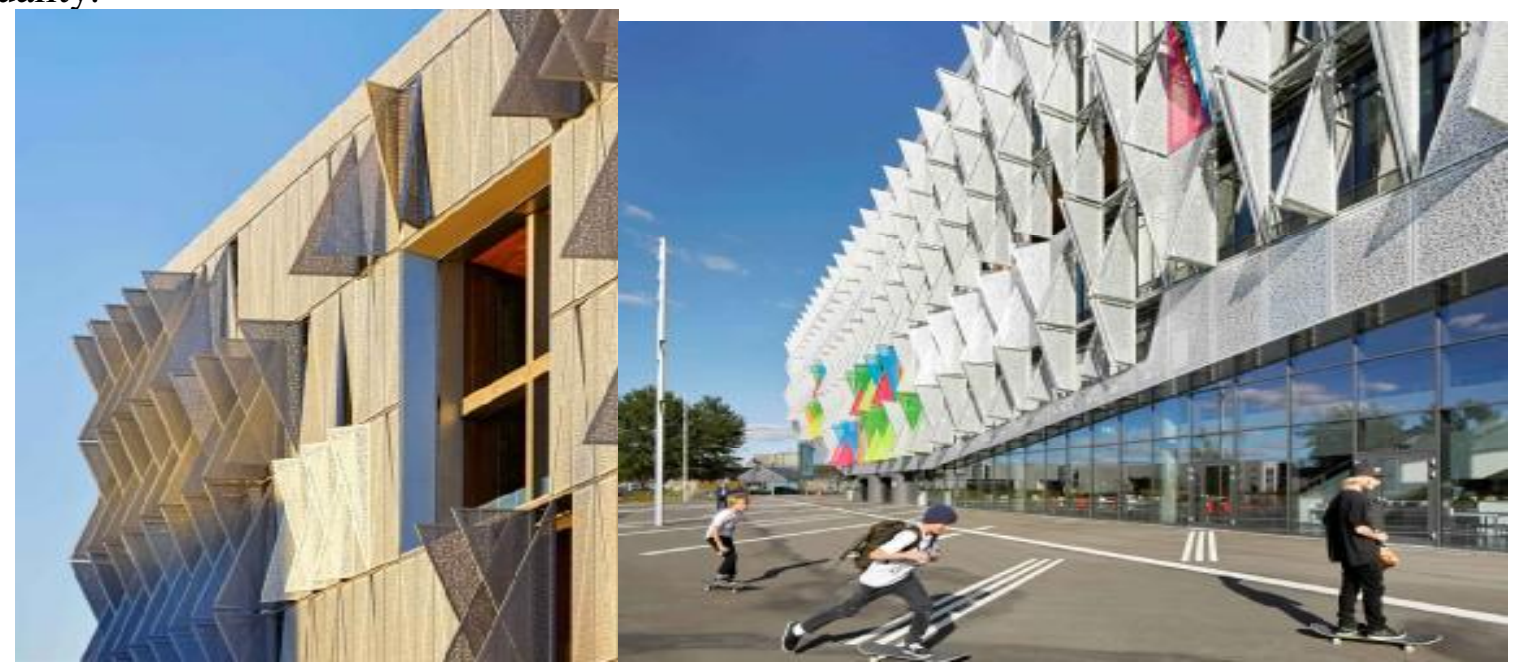

Figure (6): Southern Denmark University with the unique design and cladding

Source: arcdog.com/portfolio

\subsection{2- changing material's properties:}

This type of responsiveness to environment interface depends mainly on changing the materials properties which the facade is made out of. Material due to a certain condition like exposed to high solar radiation changes its properties in order to reduce the solar radiation entering the building.

The following example used this type of responsive architecture:

\subsubsection{1- Media-TIC Building, Spain, Barcelona 2011:}

The theme of the Media-TIC building is how architecture makes a new balance between the digital use of energy," says Ruiz Geli. ", architecture has to be a technological platform, in which connectivity, new materials and nanotechnology are important. The performative elements in the Media-TIC building are found in two of the four façades, which are made of the eco-efficient material ethylene tetrafluoroethylene (ETFE) cladding. Protection from the outside heat will be achieved using what's known as the diaphragm configuration of ETFE cladding, whereby three layers of the plastic are fixed within the triangular frame and inflated 
like a pillow. The resulting bubble contains up to three air chambers that together create a shade-effect and provide thermal insulation for the building.

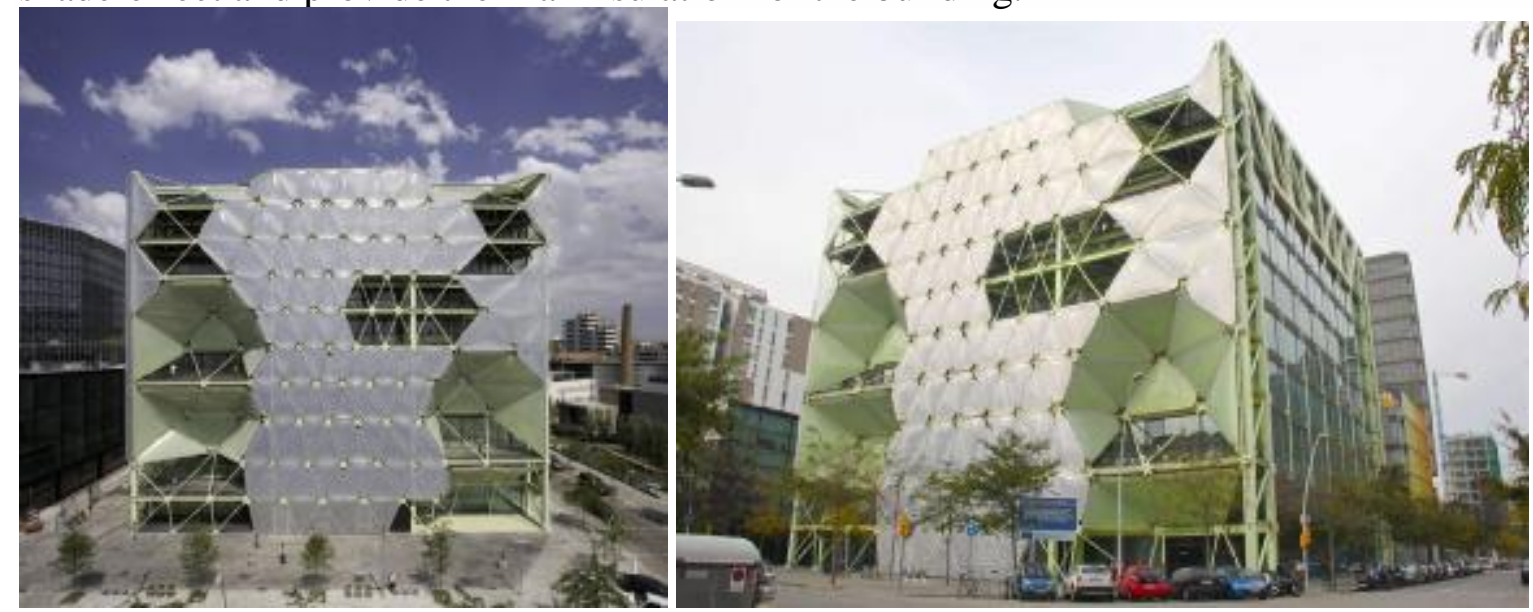

Figure(7): The main façade has a quilted appearance, owing to a sophisticated pneumatic system which lets in light or creates shade, according to the position of the sun, providing energy savings of $20 \%$. Source: latitudefortyone.com

\subsubsection{2- Heomeo-Static Facade system, New York- 2013:}

Decker Yeadon designed this building. To suit changing exterior environments, such as sunlight and temperature variations. The system composed of curvilinear surfaces made of dialectic elastomers (DE), it's a type of electro-active polymer(EAP) .Both sides of the dielectric material are coated with silver electrodes. This silver layer reflects light, and also distributes electrical charge across the material, causing it to deform. This helps the façade to regulate temperature inside the building. As a result, the elastomers open when illuminated by the sun and close with the absence of the sun .

The huge advantage of this system is highly regulated and specific solar control in a façade. This system makes the design part of the smart environment.
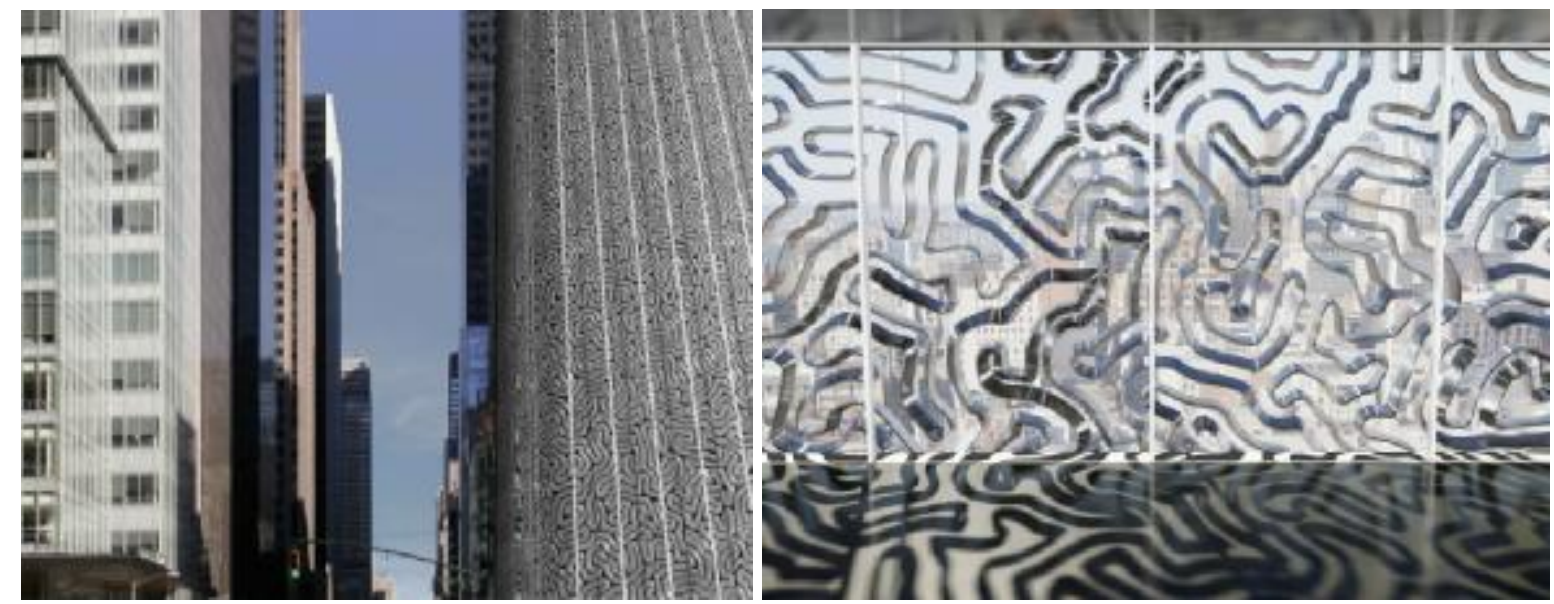

Figure (8): The silver layer that reflects light, and also distributes electrical charge across the material Source : Researchers at Tufts University School of Engineering developed magnetic elastomeric 

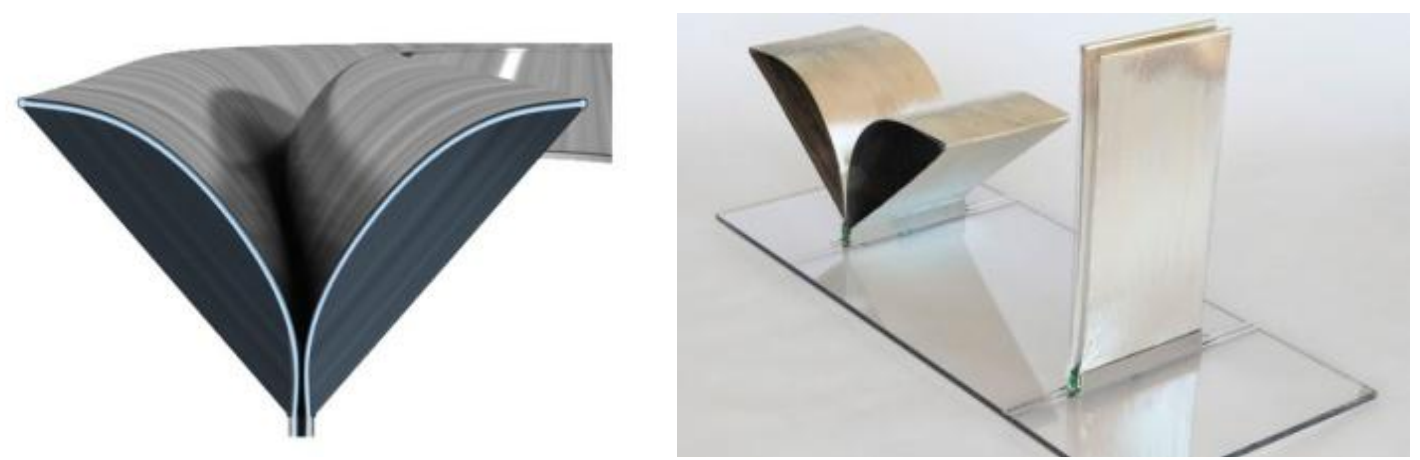

Figure (9): Section inside the material

Source: ehp.niehs.nih.gov/ 121-a18 ( 2017)

\section{- 3- Importance of Climate Responsive Design:}

It is obvious that there is a large relationship between the built environment and other problems such as environmental pollution, climatic change and energy consumption. The reason for this is due to the excessive use of heating and cooling equipment in order to enhance the indoor environment. Global awareness of these problems and seem to move towards the climate-responsive design as one of the means that can contribute to solving these problems. The most important aspects associated with Climate Responsive Design of buildings how to energy saving is its role in preserving valuable resources in our planet (AlTamimi et al. 2010). True climate-responsive architecture goes well beyond observance to rules of building only. For example, Smart glazing system offer opportunities to further the practice Electro-chromic glass actively controls how much solar light and heat transfer into at indoor.

- 4-Principles of responsive building elements:

The key principles for Responsive Building Elements (RBE) are based on the ability to perform a responsive action based on: Dynamic behavior, Adaptability, Capability to perform different functions, Intelligent control.

- 4- Energy Efficient (EE) Buildings:

Energy-efficient buildings depend on reducing the energy demand by increasing thermalperformance level. Energy consumption for heating buildings can be reduced by increasing the level of insulation, using of energy-efficient windows, kinetic and responsive facades , selecting the optimal orientation of buildings . Energy efficiency refers to the effectiveness of a building's ability to influence, control and facilitate user control over the movement of heat energy within a building and between the building and its surroundings (Ateed, 2012). Heat flow must be controlled in order to make buildings more energy efficient. It is possible to slow the rate of energy exchange through conduction, convection and radiation by increasing the thermal performance of building envelopes (Building Science, 2012). The thermal performance of buildings and the mechanisms of heat transfer in order to get a better understand of these process and their relationship with energy consumption. 


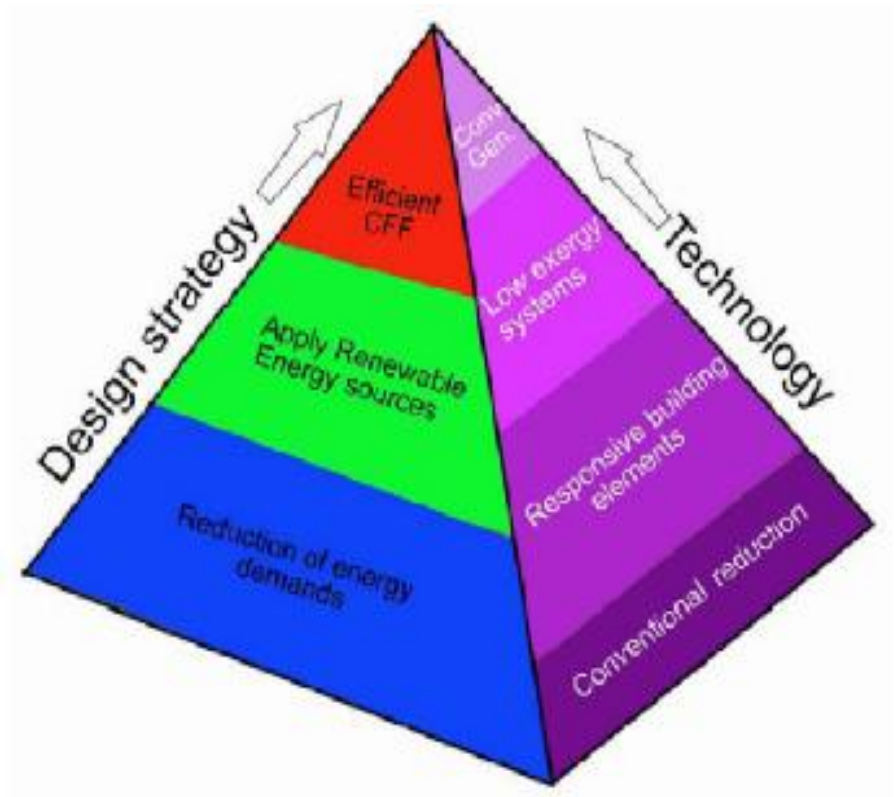

Figure (10): Design Strategy and corresponding technologies. Source: CFF:Clean fossil fuels.

\section{- 4.1- Energy Efficiency in Egypt:}

In Egypt, we found that Egypt has adopted a National Energy Efficiency Action Plan (NEEAP) (2012-2015) with cumulative energy efficiency targets of 5\%. However, there is no designated energy efficiency agency and no general legal framework for EE measures (rcreee) Egypt is by far the largest consumer of oil and natural gas in Africa, showing $22 \%$ of petroleum and other liquids of the continent's total consumption and $37 \%$ of its dry natural gas consumption ( The energy progress report 2015 ).

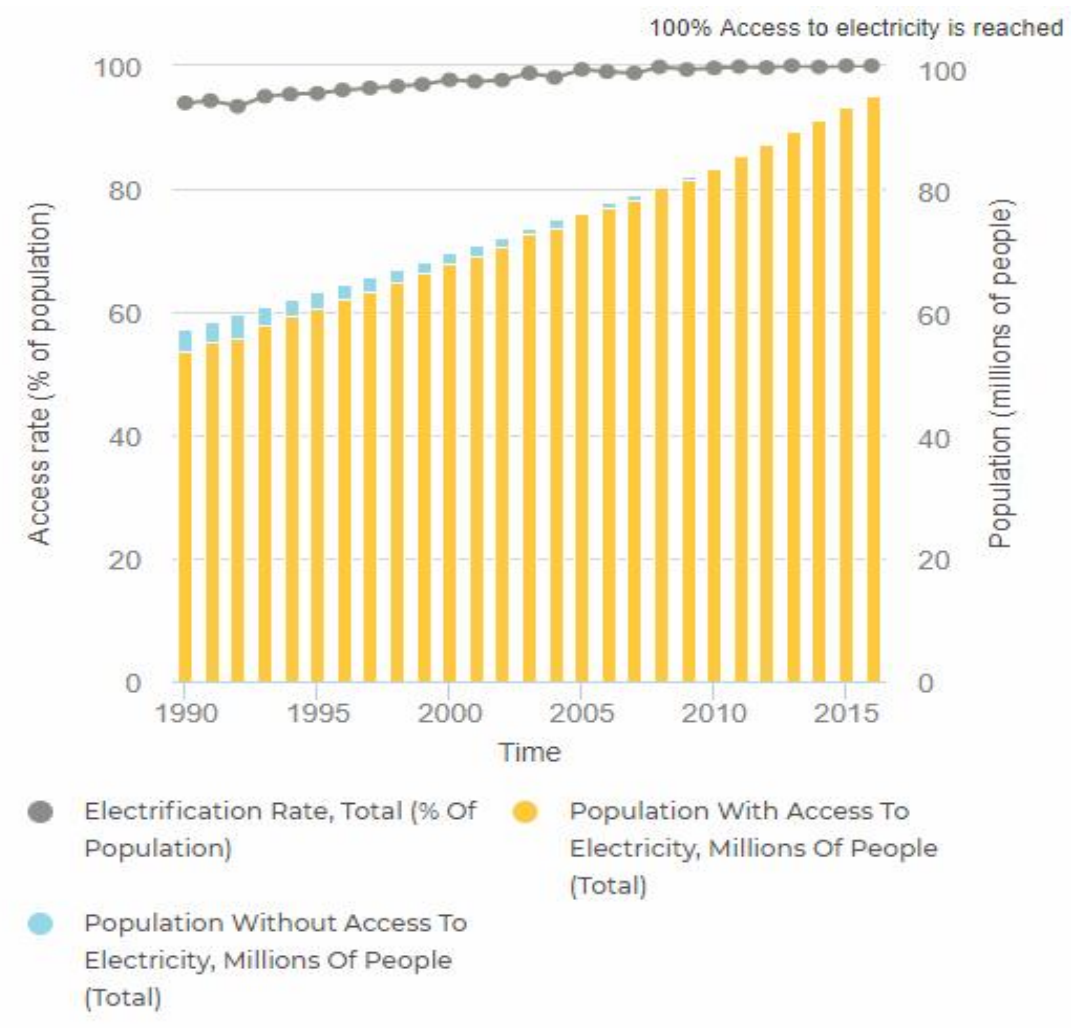

Figure(11): Total Energy Access in Egypt 1990-2015 (Tracking SDG7, 2018) Source: energypedia.info/wiki/Egypt 
THE IMPACT OF RESPONSIVE SYSTEMS ON ENERGY CONSUMPTION AND THERMAL PERFORMANCE OF BUILDINGS

This table shows a comprehensive overview of the consumption rate using different sources.

\begin{tabular}{c|c|c|c|c|c|c|c|c|c|c|}
\hline 2017 & 2016 & 2015 & 2010 & 2005 & 2000 & 1995 & 1985 & 1975 & 1965 & Year \\
\hline 91.6 & 88.2 & 84.4 & 78.4 & 60.5 & 48.4 & 37.3 & 28 & 10.5 & 7.8 & Rate \\
\hline
\end{tabular}

Table.1: Egypt's Primary Energy Consumption since 1965 in Mtoe Source: www.bp.com

Total Energy

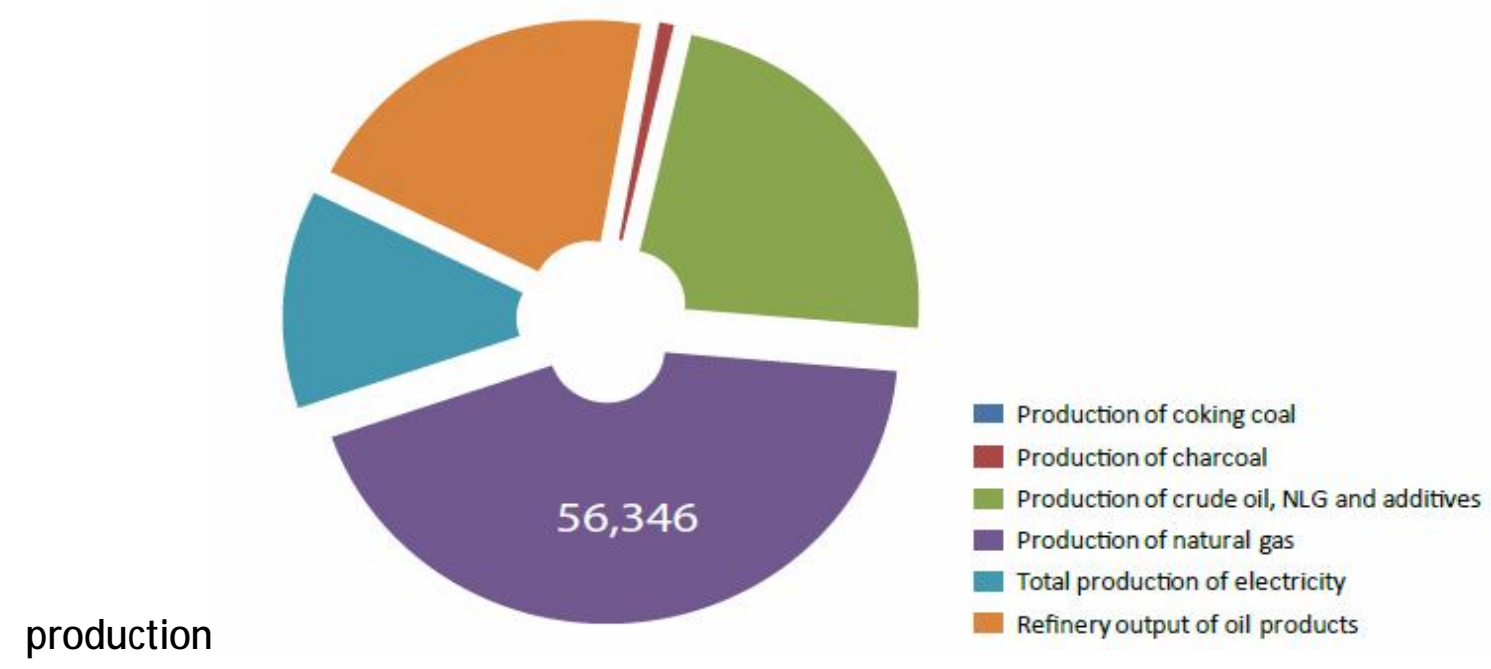

Total Energy Consumption

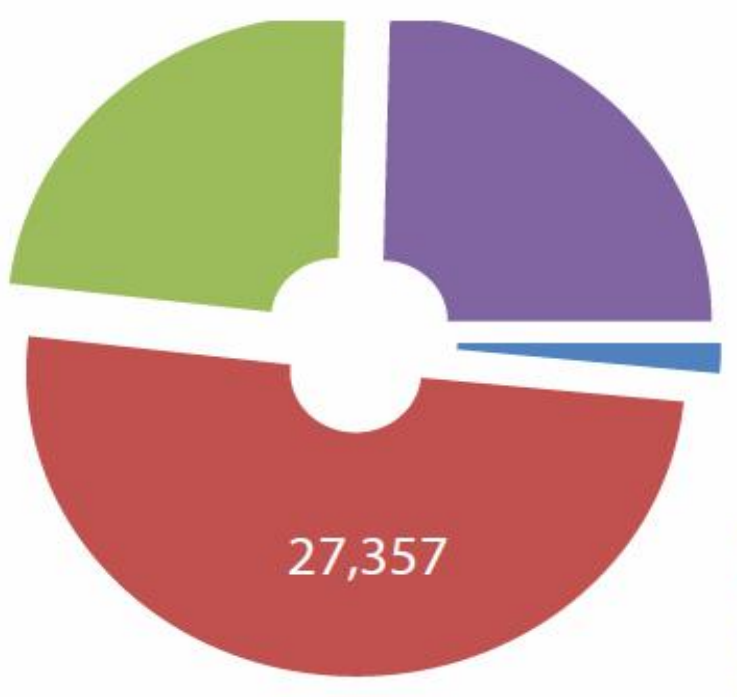

- Consumption of coking coal

- Consumption of oil

- Consumption of natural gas

- Consumption of electricity

Figure(12): Total Energy Production and Consumption in Egypt 2015 Source: (AFREC, 2015) 


\section{- 5- Responsive Building Strategies}

The main principles in design strategies are to avoid unwanted heat gain in summer and increase the heat gain and avoid heat loss in . Heat gain can be maximized in winter in an easy manner, however, it is difficult to avoid it during summer. Responsive building concepts are design solutions that maintain an appropriate balance between optimum interior conditions and environmental performance by reacting in a controlled and totalitarian way to changes in external or internal conditions and to occupant intervention. it aims to optimize energy efficiency and includes the integration of human factors and architectural considerations.

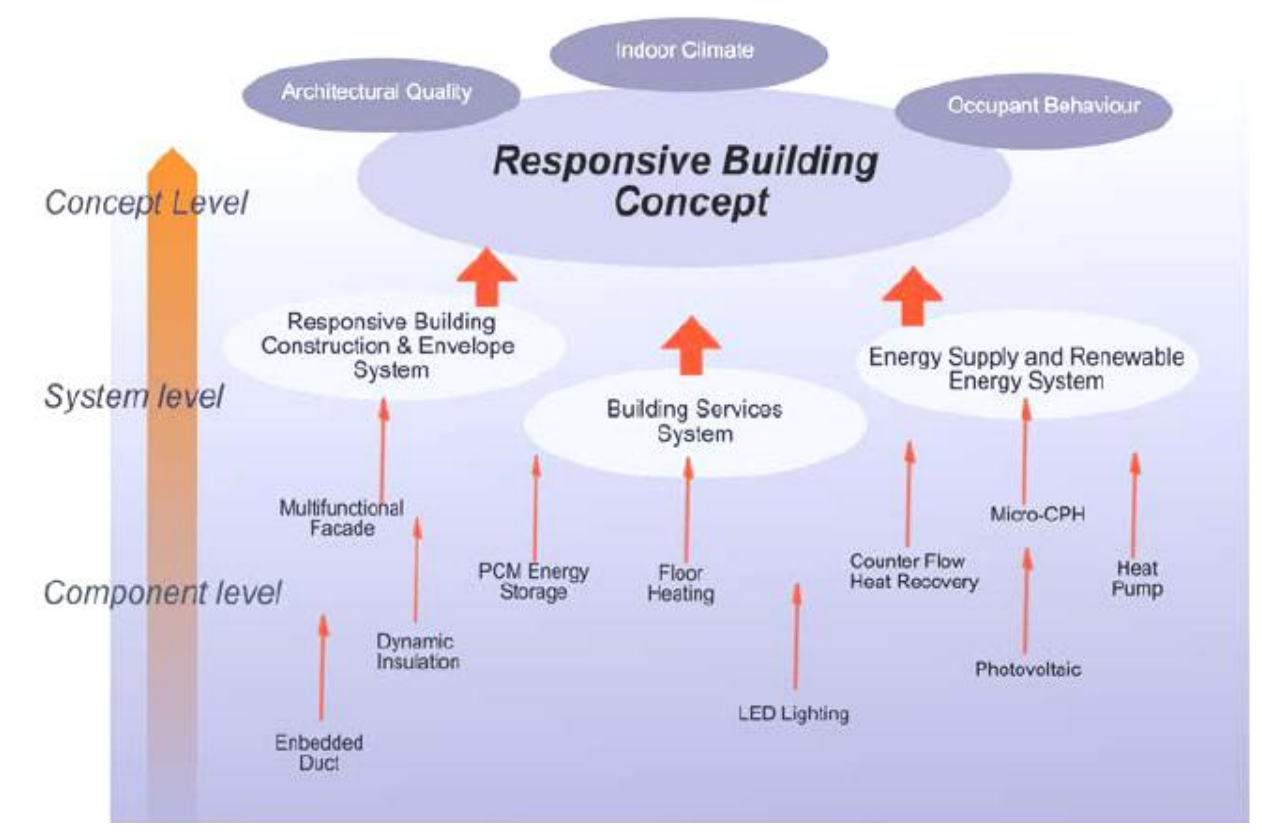

Figure (13): illustration of the Responsive Building Concept

Source: Designing with Responsive Building Elements, Klima. Bouwdelen, 2011

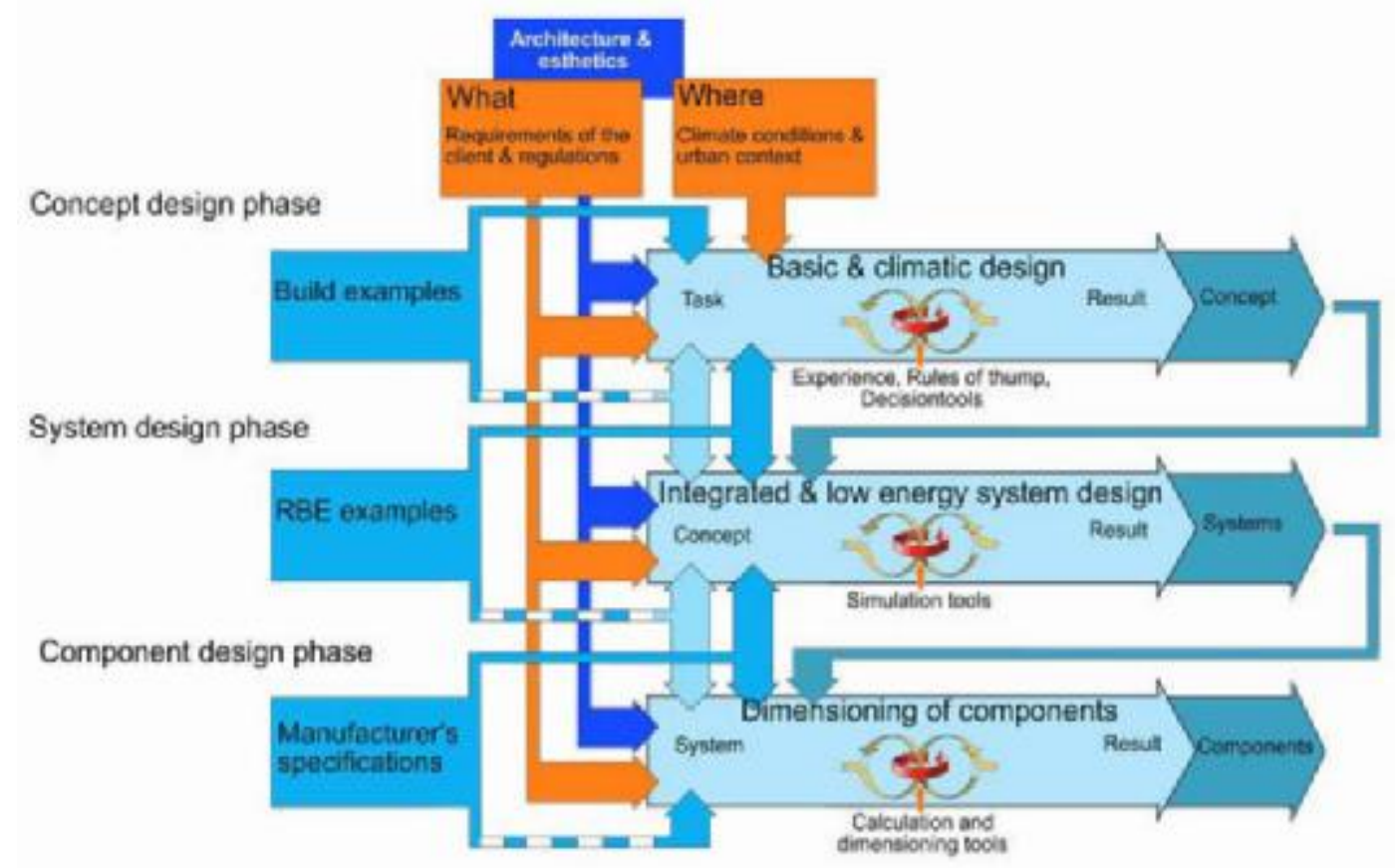

Figure (14): Design Process of Responsive Building

Source: Designing with Responsive Building Elements, Klima. Bouwdelen, 2011 


\section{6- CONCLUSIONS:}

The world is facing a significant challenge represented in the lack of conventional energy and environmental pollution related to the ever increase in energy consumption. Climatic change and global warming is another challenge which is linked to the $\mathrm{CO}_{2}$ emission from fossil fuels. The buildings contribute to these problems as they are considered the main consumers of energy and which contribute to increase the environmental pollution. Designing buildings to achieve thermal comfort is associated with studying the mechanisms of heat transfer between the building and the outdoor environment. Also, defining the means of heat gain and heat loss is essential in achieving the thermal bal

ance. The main findings of this study are:

- Buildings produce a large amount of global carbon dioxide $\left(\mathrm{CO}_{2}\right)$ emissions which increase annually at a rate of $2 \%$ from 1971 to 2004 with an annual increase of buildings.

- Façade orientation affects the energy and comfort implications of solar shading, window to wall area ratio, window position and performance and choice of exterior color.

- They can adapt to the surrounding environment by whether changing its geometric patterns or changing the properties of the facade's materials.

- Responsive system concepts are design to solve that maintain an appropriate balance between optimum interior conditions and environmental and thermal performance.

\section{7- RECOMMENDATIONS:}

ß It is necessary to utilize renewable energy sources in buildings in order to reduce environmental problems and the ever increase in using conventional sources of energy.

B Spreading awareness about the importance of activating Energy Efficient system in Egypt to achieve save energy and reduce energy consumption, then raise the thermal performance of buildings.

B It is important to eradicate the thermal transfer rate between the building envelop and the surrounding environment in order to keep the thermal balance.

\section{8- Future studies \& Research:}

- Study ways of integrating the building, and maximizing energy efficiency and improving the building's thermal performance.

- knowledge into a design strategy that assist designer into the design process in making performance based into integrated application in climate-responsive building elements .

-The role of responsive systems as a means of solving the energy consumption problem in buildings.

- Develop methods of measuring the efficiency of thermal performance in buildings continuously.

\section{REFERENCES}

1. Modin, H. (2014). Adaptive building envelopes. MSc. Thesis, Department of civil and Environmental Engineering, Division of Building Technology, Chalmers University of Technology, Sweden.

2. Addington, M., Schodek, D., (2005). Smart materials and technologies in Architecture. Architectural Press.

3. https://www.eia.gov/beta/international/analysis_includes/countries_long/Egypt/egypt.pdf.

4. http://www.rcreee.org/sites/default/files/egypt ee fact sheet print.pdf.

5. https://trackingsdg7.esmap.org/data/files/download-documents/tracking_sdg7 the_energy_progress_report_full_report.pdf 2015.

6. http://www.certainteed.com/buildingscience/energy-efficiency .

7. Al-Tamimi, N.; Fadzil, S., Harun, W. (2010). The Effects of Orientation, Ventilation, and Varied WWR on the Thermal Performance of Residential Rooms in the Tropics. Journal of Sustainable Development .

8. Climate Responsive Building-Appropriate Building Construction in Tropical and Subtropical Regions (SKAT, 1993, 324 p.) .

9. https://www.researchgate.net/figure/RBE-System-Architecture .

10. https://energypedia.info/wiki/Egypt_Energy_Situation . 
11. Material That Move: Smart Material And Intelligent Design / Murat Bengisu, Marinella Ferrara / Switzerland 2018.

12. .Http://Www.Econjournals.Com/Index.Php/Ijeep/About/ Submissions?Fbclid=Iwar3czismltchmbdx6zsi4xxc7axibtsdhbnvbuyuibn4hsfghdbifp0yrw\#Authorguidelines .

13. Http://Arcdog.Com/Portfolio/Sdu-University-Of-Southern-Denmark-CampusKolding/?Fbclid=Iwar2dwqanosgxuxpkfgwlcz9vjmbvodpurbciphk0llkadbjprp3lgmb_Mzc .

14. Https://Www.Ipcc.Ch/Sr15/?Fbclid=Iwar2zfnr8q7ex3vzvg5w_91skghd1d9luull1zvcn9ne4dqh nqx7egq_Ktcg.

15. Https://Www.Indexmundi.Com/?Fbclid=Iwar2t3j0dvdoug1gw8ro9eOdijmidr7xs4rbe9wflfggt9kanzegxgmn67m . 